\section{BRAZIULIAN JOURNAL}

OF MEDICAL AND BIOLOGICAL RESFARCH

www.bjournal.com.br
ISSN 0100-879X

Volume 43 (11) 1010-1134 November 2010

BIOMEDICAL SCIENCES

AND

CLINICAL INVESTIGATION

Braz J Med Biol Res, November 2010, Volume 43(11) 1084-1087

doi: 10.1590/S0100-879X2010007500109

Coronary artery calcification is associated with insulin resistance index in patients with type 1 diabetes

T.C. Rodrigues, K. Biavatti, F.K. Almeida and J.L. Gross

The Brazilian Journal of Medical and Biological Research is partially financed by
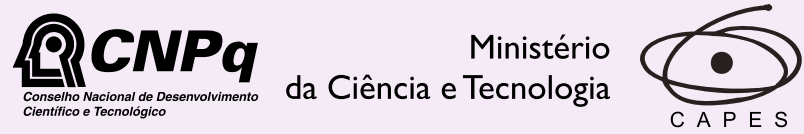

Ministério da Educação

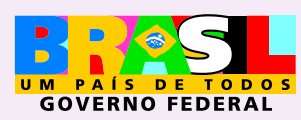

DFAPESP

Institutional Sponsors
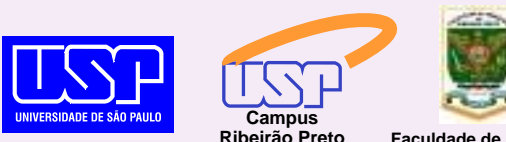

$\oplus$ SHIMADZU

GE Healthcare
Hotsite of proteomics metabolomics developped by: 


\title{
Coronary artery calcification is associated with insulin resistance index in patients with type 1 diabetes
}

\author{
T.C. Rodrigues, K. Biavatti, F.K. Almeida and J.L. Gross \\ Serviço de Endocrinologia, Hospital de Clínicas de Porto Alegre, \\ Universidade Federal do Rio Grande do Sul, Porto Alegre, RS, Brasil
}

\begin{abstract}
The objective of the present study was to evaluate the risk factors associated with the presence of coronary artery calcification (CAC) in patients with type 1 diabetes (T1D). A cross-sectional study was conducted on 100 consecutive T1D patients without coronary artery disease, with at least 5 years of diabetes and absence of end-stage renal disease. Mean age was $38 \pm 10$ years and $57 \%$ were males. CAC score was measured by multidetector computed tomography (Siemens Sensation 64 Cardiac). The insulin resistance index was measured using the estimated glucose disposal rate (eGDR). The eGDR was lower among CAC-positive patients than among CAC-negative patients, suggesting an increased insulin resistance. In a logistic regression model adjusted for age (at 10-year intervals), eGDR, diabetic nephropathy and gender, CAC was associated with age [OR $=2.73(95 \% \mathrm{Cl}=1.53-4.86), \mathrm{P}=0.001]$ and with eGDR $[\mathrm{OR}=0.08(95 \% \mathrm{Cl}=0.02-0.21), \mathrm{P}=0.004]$. In T1D subjects, insulin resistance is one of the most important risk factors for subclinical atherosclerosis.
\end{abstract}

Key words: Type 1 diabetes; Coronary artery calcification; Insulin resistance

\section{Introduction}

Patients with type 1 diabetes (T1D) are at increased risk for coronary artery disease (CAD) (1). The detection of coronary artery calcification (CAC) has been used as a new tool to assess CAD and to predict coronary events beyond standard risk factors in the general population, independent of the presence of diabetes (2). There is a good correlation between CAC and coronary atherosclerotic plaque burden (3) and CAC is a powerful predictor of clinical CAD in non-diabetic subjects (4). Patients with diabetes have higher CAC scores than non-diabetic individuals (5), including a greater extent and progression of CAC than non-diabetic subjects (6). The presence of CAC is correlated with CAD in both men and women with T1D (7). The factors associated with the presence of CAC in patients with T1D are still not fully defined. Insulin resistance in T1D subjects increases progressively with disease duration and its prevalence in these patients is 12 to $42 \%$ (8-11). Moreover, insulin resistance has been associated with micro- and macrovascular complications in individuals with T1D (11-13). Although prospective data for the power of CAC to predict coronary heart disease events in
T1D subjects are still lacking, measurement of CAC could help in deciding about preventive therapy in this group of patients. Therefore, the aim of the present study was to evaluate the risk factors associated with the presence of subclinical atherosclerosis, assessed by CAC, in a sample of T1D patients and especially to evaluate the association between $\mathrm{CAC}$ and insulin resistance.

\section{Material and Methods}

We performed a cross-sectional study on 100 consecutive T1D patients attending the Endocrine Division's outpatient clinic at Hospital de Clínicas de Porto Alegre. These patients are part of a cohort that has been followed since 2000. T1D was defined as onset of diabetes before the age of 40 years, a previous episode of ketoacidosis or documented ketonuria, and mandatory use of insulin for survival. Inclusion criteria were age $>18$ years, at least 5 years duration of diabetes, absence of end-stage renal disease (dialysis or renal transplant) and absence of known cardiovascular disease defined on the basis of a normal

Correspondence: T.C. Rodrigues, Serviço de Endocrinologia, Hospital de Clínicas de Porto Alegre, UFRGS, Rua Ramiro Barcelos, 2350, Prédio 12, 4º andar, 90035-003 Porto Alegre, RS, Brasil. Fax: +55-51-2101-8777. E-mail: ticianacr@yahoo.com.br

Received January 28, 2010. Accepted August 27, 2010. Available online October 15, 2010. Published November $12,2010$. 
resting ECG and a negative medical history of myocardial infarction, angina, intermittent claudication, coronary artery revascularization procedure, or stroke. Mean age of the patients in this study was $38 \pm 10$ years, the proportion of males was $57 \%$, and the mean duration of diabetes was $18 \pm 9$ years.

The Ethics Committee of the Hospital approved the study, and informed written consent was obtained from all patients.

\section{Patient evaluation}

All T1D patients answered a standardized questionnaire as previously described (14), and underwent a complete physical examination including measurement of waist circumference (mid-axillary line midway between the highest point of the iliac crest and lowest point of the costal margin), height, and weight while wearing light clothing and no shoes. Body index mass was calculated as weight $(\mathrm{kg}) / \mathrm{height}^{2}$ (m). Blood pressure (BP) was measured twice in the sitting position after a 10-min rest with a standard 12.5-cm cuff mercury sphygmomanometer (Korotkoff phases I and IV). The mean of 2 measures was used for analysis. Hypertension was considered to be present if systolic BP levels were $\geq 130 \mathrm{mmHg}$ and/or diastolic BP was $\geq 85 \mathrm{mmHg}$, or if the patient was using antihypertensive medication. After fasting for $12 \mathrm{~h}$, a blood sample was obtained by venipuncture from each subject. Patients with microalbuminuria [urinary albumin excretion rate (UAER) $\geq 20$ and $\leq 200 \mu \mathrm{g} / \mathrm{min}$ ] and macroalbuminuria (UAER $>200 \mu \mathrm{g} / \mathrm{min}$ ) were analyzed as a diabetic nephropathy group.

\section{Laboratory measurements}

UAER was measured by immunoturbidimetry (Microal; Ames-Bayer, USA; intra- and interassay coefficients of variation of 4.5 and $11 \%$, respectively). Hemoglobin (A1c) was measured by a high-performance liquid chromatography (normal range 4-6\%; Merck-Hitachi 9100, Germany). Fasting plasma glucose was measured by the glucose-peroxidase colorimetric enzymatic method (Biodiagnostica, Brazil), serum creatinine by the Jaffé method, and the glomerular filtration rate was estimated (eGFR) using the formula of the Modification of Diet in Renal Disease Study (15). The lipid profile was measured by an enzymatic-colorimetric method (Merck Diagnostica; Boeringher Mannheim, Germany). Estimated glucose disposal rate (eGDR), a measure of insulin sensitivity, was calculated using an equation involving $\mathrm{A} 1 \mathrm{c}$, waist-to-hip ratio and hypertension derived from hyperinsulinemic-euglycemic clamp studies (16).

\section{Coronary artery calcification}

CAC was measured with a multidetector computed tomography (CT) system that acquired 64 simultaneous 2.5-mm slices for each cardiac cycle with prospective ECG-triggered scan acquisition at $60 \%$ of the RR interval in a sequential scan mode (Somaton Sensation 64 Cardiac,
Siemens Medical Solutions, Germany). All scans were analyzed for the presence of CAC on an offline workstation (Circulation, Siemens). A calcified lesion was defined as an area with $\mathrm{CT}$ attenuation $>130$ Hounsfield units $(\mathrm{HU})$. The Agatston score was calculated by multiplying the area of each lesion by a weighted CT attenuation score, depending on the maximal CT attenuation $(\mathrm{HU})$ within the lesion. The cardiologist reading the CT scans was unaware of the clinical data.

\section{Statistical analysis}

The Student $t$-test and the $x^{2}$ test were used to compare clinical and laboratory data and Pearson correlation was determined. Data with a normal distribution are reported as means $\pm S D$, and quantitative variables without a normal distribution (UAER, triglycerides, CAC score, and eGDR) are reported as median and range and were log transformed before analysis. The CAC score was added to the number 1 and then log transformed [log $(C A C+1)]$. Models of multiple logistic regression analysis were used with the presence of CAC (>zero) as the dependent variable and age (at 10-year intervals), gender and eGDR as independent variables. $P$ values $<0.05$ (two-tailed) were considered to be significant.

\section{Results}

Of 100 patients evaluated, 31 were CAC-positive. Clinical and laboratory data are described in Table 1. CAC-positive patients were older, had a longer duration of diabetes and were more frequently hypertensive. CAC-positive women had a higher waist/hip ratio (WHR), an association that was not observed among men. The eGDR was lower among CAC-positive patients compared to CAC-negative patients, suggesting an increased insulin resistance in subjects with CAC. Lipid profile, glycemic control and the mean dose of insulin did not differ between the two groups.

In the univariate analysis, the proportion of patients with CAC did not differ between men $(21 / 58=36 \%)$ and women $(10 / 42=24 \% ; P=0.20)$ nor did the amount of CAC $(P=0.22)$. Among 31 CAC-positive patients, 9 had CAC $>100 \mathrm{HU}$ and 22 had CAC between $>$ zero and $\leq 100 \mathrm{HU}$. In patients with the presence of CAC, the amount of calcium in the coronaries had a significant positive correlation with age $(r=0.56 ; P<0.001)$, diabetes duration $(r=0.30, P=$ $0.003)$, WHR ( $r=0.30 ; P=0.003)$ and a negative correlation with eGDR $(r=-0.40 ; P<0.001)$ and eGFR $(r=-0.20 ; P=$ $0.04)$. UAER, BP values and lipid profile did not correlate with the extent of CAC.

To analyze a possible association between cardiovascular risk factors and the presence of CAC, a logistic regression model was performed with the presence of CAC as the dependent variable and age (at 10-year intervals), gender and eGDR as independent variables. Age [OR = $2.73(95 \% \mathrm{Cl}=1.53-4.86), \mathrm{P}=0.001]$ and eGDR $[\mathrm{OR}=0.08$ 
$(95 \% \mathrm{Cl}=0.02-0.21), \mathrm{P}=0.004]$ were associated with the presence of CAC, whereas male gender $[\mathrm{OR}=1.20(95 \% \mathrm{Cl}$ $=0.40-3.47), P=0.76]$ was not. Next, we tested for interaction between gender and eGDR, which was significant $(P=$ $0.01)$. There was no interaction between gender and age. For a better understanding of the interaction, we showed the odds ratio of eGDR by gender (Table 2 ).

Additionally, we evaluated the presence of metabolic syndrome (MetS; NCEP criteria; http://www.americanheart.org/presenter.jhtml?identifier=4756). Patients with MetS more frequently presented CAC [10/19 (52.6\%)] than patients without MetS [21/81 (25.9\%)], $P=0.023$. CAC scores were higher $(P=0.006)$ in patients with MetS [2.0 HU (0.0-1364), $\mathrm{N}=19]$ than in patients without MetS [0.0 HU (0.0-1410), $N=81]$. The proportion of patients with CAC did not differ between men $(21 / 58=36 \%)$ and women $(10 / 32=31 \%, P=0.20)$. In addition, we performed a logistic regression including MetS, gender and age (at 10-year intervals) as independent variables and the presence of CAC as the dependent variable. MetS and gender did not remain associated with outcome and only age [OR $=3.62(95 \% \mathrm{Cl}=2.17-6.05), \mathrm{P}<0.001]$ was related to the presence of CAC.

\section{Discussion}

An association between the presence of CAC and age and insulin resistance (assessed by eGDR) was observed in the present study. Additionally, we observed an interaction between insulin resistance and gender in female T1D subjects with CAC.

One third of the patients had CAC. It is known that patients with T1D have more CAC than non-diabetic patients (6) and that CAC increases with age in T1D subjects and in non-diabetic subjects (12). The odds ratio for an increase in CAC was 2.73 times for every 10 additional years of age. Insulin resistance, as assessed by eGDR, was validated by Williams et al. (16) in patients with T1D to determine the degree of insulin sensitivity. It is easy to calculate and shows a close correlation with insulin resistance determined by the clamp method (16). Moreover, eGDR has been described as a predictor of cardiovascular outcomes and microvascular complications in prospective studies with T1D $(12,17,18)$ and has been shown to be independently associated with CAC in patients with T1D, thus possibly explaining the greater CAC seen in women than in men among T1D subjects (6). Recently, eGDR was reported to be associated with CAD only in women with T1D (11). We observed an interaction between female gender and insulin resistance index, probably because our female group with CAC had a higher WHR than the female group without CAC. Visceral obesity was an independent predictor of CAC progression in a study with older adults without known heart disease (19). Recently eGDR, as an insulin resistance marker, provided more useful information than other classical variables such as insulin requirements, to predict vascular complications in a cohort of T1D individuals (13). In our sample, eGDR was a better predictor of the presence of CAC than the presence of MetS.

The lack of association between $\mathrm{CAC}$ and BP values and between CAC and UAER can be explained by the fact that these patients were taking antihypertensive medica-

Table 1. Clinical characteristics of patients with type 1 diabetes according to the presence of coronary artery calcification.

\begin{tabular}{|c|c|c|}
\hline & $\mathrm{CAC}+(\mathrm{N}=31)$ & CAC- $(\mathrm{N}=69)$ \\
\hline Age (years) & $47 \pm 9^{*}$ & $35 \pm 9$ \\
\hline Diabetes duration (years) & $23 \pm 11^{*}$ & $16 \pm 7$ \\
\hline Race (white), N (\%) & $28(90.3)$ & $60(87.1)$ \\
\hline Men, N (\%) & $21(67.7)$ & $38(55.1)$ \\
\hline \multicolumn{3}{|l|}{ Waist/hip ratio } \\
\hline Men & $0.86 \pm 0.06$ & $0.85 \pm 0.04$ \\
\hline Women & $0.86 \pm 0.06^{*}$ & $0.78 \pm 0.05$ \\
\hline $\mathrm{BMI}\left(\mathrm{kg} / \mathrm{m}^{2}\right)$ & $25 \pm 3.5$ & $25 \pm 3.4$ \\
\hline Systolic blood pressure (mmHg) & $126 \pm 17$ & $120 \pm 15$ \\
\hline Diastolic blood pressure (mmHg) & $77 \pm 9$ & $77 \pm 11$ \\
\hline Hypertension, N (\%) & $18(58)^{*}$ & $16(23)$ \\
\hline Current smokers, N (\%) & $4(12)$ & $8(12)$ \\
\hline Insulin dose $/ \mathrm{kg}\left(\mathrm{U} \cdot \mathrm{kg}^{-1} \cdot \mathrm{day}^{-1}\right)$ & $0.69 \pm 0.29$ & $0.70 \pm 0.20$ \\
\hline eGDR $\left(\mathrm{mg} \cdot \mathrm{kg}^{-1} \cdot \mathrm{min}^{-1}\right)$ & $5.7(3.2-10.6)^{*}$ & $8.7(3.4-11.2)$ \\
\hline UAER $(\mu \mathrm{g} / \mathrm{min})$ & $9.7(3.5-1251)$ & $8.8(0.9-476)$ \\
\hline Total cholesterol (mg/dL) & $179 \pm 40$ & $177 \pm 49$ \\
\hline $\mathrm{HDL}(\mathrm{mg} / \mathrm{dL})$ & $59 \pm 21$ & $57 \pm 13$ \\
\hline LDL (mg/dL) & $100 \pm 30$ & $102 \pm 44$ \\
\hline Triglycerides (mg/dL) & $89(37-212)$ & $68(30-706)$ \\
\hline $\mathrm{A} 1 \mathrm{c}(\%)$ & $8.2 \pm 1.6$ & $8.6 \pm 1.9$ \\
\hline GFR $\left(\mathrm{mL} \cdot \mathrm{min}^{-1} \cdot\left(1.73 \mathrm{~m}^{2}\right)^{-1}\right)$ & $76 \pm 29$ & $86 \pm 27$ \\
\hline Diabetic nephropathy, N (\%) & $12(38)$ & $14(20)$ \\
\hline
\end{tabular}

$\mathrm{CAC}=$ coronary artery calcification measured by multidetector computed tomography; BMI = body mass index; eGDR = estimated glucose disposal rate; UAER = urinary albumin excretion rate; GFR = glomerular filtration rate. ${ }^{*} \mathrm{P}<0.05 \mathrm{CAC}+$ vs CAC( $t$-test or $\mathrm{X}^{2}$ test).

Table 2. Odds ratio for the presence of coronary artery calcification by gender.

\begin{tabular}{lccc}
\hline & OR & $95 \% \mathrm{Cl}$ & $\mathrm{P}$ \\
\hline $\begin{array}{l}\text { Female patients } \\
\text { Age (per 10 years) }\end{array}$ & 3.78 & $1.38-10.36$ & 0.009 \\
eGDR & 0.42 & $0.24-0.72$ & 0.002 \\
Male patients & & & \\
Age (per 10 years) & 3.62 & $1.70-7.74$ & 0.001 \\
eGDR & 0.73 & 1.26 & 0.79 \\
\hline
\end{tabular}

eGDR = estimated glucose disposal rate. 
tion and had a good BP control (126/77 vs 120/77 mmHg). Furthermore the number of patients with nephropathy was small $(\mathrm{N}=26)$.

Curiously, in our study, male gender was not a risk for the presence of CAC, probably because male patients with CAC had a smaller abdominal circumference than males without CAC, a fact that could have increased their insulin sensitivity.

Small sample size is a limitation of the present study. Of note, our cohort showed that women with T1D and visceral

\section{References}

1. Laing SP, Swerdlow AJ, Slater SD, Botha JL, Burden AC, Waugh NR, et al. The British Diabetic Association Cohort Study, II: cause-specific mortality in patients with insulintreated diabetes mellitus. Diabet Med 1999; 16: 466-471.

2. Budoff MJ, Achenbach S, Blumenthal RS, Carr JJ, Goldin JG, Greenland P, et al. Assessment of coronary artery disease by cardiac computed tomography: a scientific statement from the American Heart Association Committee on Cardiovascular Imaging and Intervention, Council on Cardiovascular Radiology and Intervention, and Committee on Cardiac Imaging, Council on Clinical Cardiology. Circulation 2006; 114: 1761-1791.

3. Sangiorgi G, Rumberger JA, Severson A, Edwards WD, Gregoire J, Fitzpatrick LA, et al. Arterial calcification and not lumen stenosis is highly correlated with atherosclerotic plaque burden in humans: a histologic study of 723 coronary artery segments using nondecalcifying methodology. J Am Coll Cardiol 1998; 31: 126-133.

4. Raggi P, Callister TQ, Cooil B, He ZX, Lippolis NJ, Russo DJ, et al. Identification of patients at increased risk of first unheralded acute myocardial infarction by electron-beam computed tomography. Circulation 2000; 101: 850-855.

5. Schurgin S, Rich S, Mazzone T. Increased prevalence of significant coronary artery calcification in patients with diabetes. Diabetes Care 2001; 24: 335-338.

6. Dabelea D, Kinney G, Snell-Bergeon JK, Hokanson JE, Eckel RH, Ehrlich J, et al. Effect of type 1 diabetes on the gender difference in coronary artery calcification: a role for insulin resistance? The Coronary Artery Calcification in Type 1 Diabetes (CACTI) Study. Diabetes 2003; 52: 2833-2839.

7. Olson JC, Edmundowicz D, Becker DJ, Kuller LH, Orchard TJ. Coronary calcium in adults with type 1 diabetes: a stronger correlate of clinical coronary artery disease in men than in women. Diabetes 2000; 49: 1571-1578.

8. Thorn LM, Forsblom C, Fagerudd J, Thomas MC, Pettersson-Fernholm K, Saraheimo M, et al. Metabolic syndrome in type 1 diabetes: association with diabetic nephropathy and glycemic control (the FinnDiane study). Diabetes Care 2005; 28: 2019-2024.

9. Pambianco G, Costacou T, Orchard TJ. The prediction of major outcomes of type 1 diabetes: a 12-year prospective evaluation of three separate definitions of the metabolic syndrome and their components and estimated glucose disposal rate: the Pittsburgh Epidemiology of Diabetes Complications Study experience. Diabetes Care 2007; 30: obesity had an additional risk for subclinical atherosclerosis and that subclinical atherosclerosis was associated with age and with insulin resistance in T1D subjects.

\section{Acknowledgments}

Research partially supported by PRONEX, FAPERGS and FIPE (Fundo de Incentivo a Pesquisa e Eventos HCPA).
1248-1254.

10. Davis TM, Bruce DG, Davis WA. Prevalence and prognostic implications of the metabolic syndrome in community-based patients with type 1 diabetes: the Fremantle Diabetes Study. Diabetes Res Clin Pract 2007; 78: 412-417.

11. Kilpatrick ES, Rigby AS, Atkin SL. Insulin resistance, the metabolic syndrome, and complication risk in type 1 diabetes: "double diabetes" in the Diabetes Control and Complications Trial. Diabetes Care 2007; 30: 707-712.

12. Orchard TJ, Olson JC, Erbey JR, Williams K, Forrest KY, Smithline $\mathrm{KL}$, et al. Insulin resistance-related factors, but not glycemia, predict coronary artery disease in type 1 diabetes: 10-year follow-up data from the Pittsburgh Epidemiology of Diabetes Complications Study. Diabetes Care 2003; 26: 1374-1379.

13. Chillaron JJ, Goday A, Flores-Le-Roux JA, Benaiges D, Carrera MJ, Puig J, et al. Estimated glucose disposal rate in assessment of the metabolic syndrome and microvascular complications in patients with type 1 diabetes. J Clin Endocrinol Metab 2009; 94: 3530-3534.

14. da Costa Rodrigues T, Pecis M, Azevedo MJ, Esteves JF, Gross JL. Ambulatory blood pressure monitoring and progression of retinopathy in normotensive, normoalbuminuric type 1 diabetic patients: a 6-year follow-up study. Diabetes Res Clin Pract 2006; 74: 135-140.

15. Levey AS, Coresh J, Balk E, Kausz AT, Levin A, Steffes MW, et al. National Kidney Foundation practice guidelines for chronic kidney disease: evaluation, classification, and stratification. Ann Intern Med 2003; 139: 137-147.

16. Williams KV, Erbey JR, Becker D, Arslanian S, Orchard TJ. Can clinical factors estimate insulin resistance in type 1 diabetes? Diabetes 2000; 49: 626-632.

17. Olson JC, Erbey JR, Williams KV, Becker DJ, Edmundowicz D, Kelsey SF, et al. Subclinical atherosclerosis and estimated glucose disposal rate as predictors of mortality in type 1 diabetes. Ann Epidemiol 2002; 12: 331-337.

18. Ruppert K, Roberts MS, Orchard TJ, Zgibor JC. Cardiovascular disease risk prediction in type 1 diabetes: accounting for the differences. Diabetes Res Clin Pract 2007; 78: 234237.

19. Kramer CK, von Muhlen D, Gross JL, Barrett-Connor E. A prospective study of abdominal obesity and coronary artery calcium progression in older adults. J Clin Endocrinol Metab 2009; 94: 5039-5044. 